\title{
Commentary Breast cancer in Marin County
}

Alice S Whittemore

Stanford University School of Medicine, Stanford, California, USA

Correspondence: Alice S Whittemore (e-mail: alicesw@stanford.edu)

Published: 28 July 2003

Breast Cancer Res 2003, 5:232-234 (DOI 10.1186/bcr633)

(C) 2003 BioMed Central Ltd (Print ISSN 1465-5411; Online ISSN 1465-542X)

See related Research articles: http://breast-cancer-research.com/content/4/6/R13; http://breast-cancer-research.com/content/5/4/R88

\begin{abstract}
Two articles previously published in Breast Cancer Research illustrate the high rates of breast cancer in Marin County, a wealthy, urban county immediately northwest of the city of San Francisco. I herein comment on these articles, and on the political/psychological/scientific dilemma presented by regions with high cancer rates, such as Marin County. I discuss possible causes for such cancer 'clusters', and conclude with some thoughts about the future.
\end{abstract}

Keywords: breast cancer, cancer cluster, genetic factors, risk heterogeneity, socioeconomic status

\section{Introduction}

Two articles previously published in Breast Cancer Research provide another example of the political/social/ psychological/scientific quandary presented by regional cancer clusters $[1,2]$. A community is concerned by what it perceives to be its high incidence of cancer, and a group of activists collaborates with epidemiologists to investigate the reasons for the cluster. They launch a study that considers every conceivable cause, but cannot come up with an answer because of limitations in their study design.

\section{Findings of the articles}

Marin County is a small urban county north of San Francisco. Its 250,000 predominantly white, non-Hispanic residents have breast cancer rates approximately 38\% higher than those of the United States as a whole [1]. In response to concerns about these high rates, breast cancer activists teamed with cancer epidemiologists to conduct a case-control study within Marin County.

The paper by Wrensch and colleagues reports the results of this comparison of personal and environmental risk factors among 285 breast cancer cases and 286 control women [1]. The authors found more frequent screening for breast cancer, and longer and heavier alcohol consumption, among cases compared with controls. They did not, respect to several other established breast cancer risk factors, including a family history of the disease and low parity. Moreover, cases and controls were similar with respect to age at first residence and to total years of residence in Marin County. This similarity fails to support exposure to a regional environmental toxicant as an explanation for the cluster. A limitation of this study is its low power for detecting case-control differences in risk factors for the disease, given the homogeneity of the women in the county with respect to socioeconomic status and its concomitants. A more informative study would have compared the distribution of established risk factors in Marin County with those in other California urban counties, to evaluate how much of the excess might be due to any unfavorable distribution of risk factors in Marin County.

The paper by Clarke and colleagues compares breast cancer rates and trends in the period 1990-1999 in Marin County with those in other urban counties in the San Francisco Bay Area and elsewhere in California [2]. The investigators found that rates increased more rapidly during this period in Marin County than in the other counties. Mortality rates remained constant in Marin County, while they declined elsewhere. The authors conclude that these differences are probably explained by Marin County's unique sociodemographic characteristics. They have shown that the higher breast cancer rate in Marin County has persisted for 10 years. 


\section{The problem}

Neither of these studies provides the definitive answer to the reasons for the cluster for which the breast cancer activists had hoped $[1,2]$. State and provincial health departments are burgeoning with records of similar inconclusive attempts to determine the causes of regional cancer clusters. When the cancer rates in a region show statistically significant excess compared with rates elsewhere, legislators and public health officials feel compelling political and social pressure to respond to the perceived threat by mandating epidemiological studies.

The apparent breast cancer cluster on Long Island, which is remarkably similar to that in Marin County, illustrates this point. Elevated breast cancer rates in two Long Island counties prompted breast cancer activists to lobby for research to uncover the environmental toxicants responsible for the cluster. The outcome was the Long Island Breast Cancer Study Project, mandated by the US Congress in 1993. The cornerstone of the Long Island Breast Cancer Study Project was a 7-year, $\$ 8$ million case-control study, the most comprehensive ever conducted to link breast cancer with environmental toxicants. The study has produced largely negative results $[3,4]$. Its case-control design is suboptimal for its goals because it cannot evaluate long-term exposures to the many toxicants having short half-lives in the body. However, the investigators had little flexibility in choosing a design because US Congress mandated a case-control study. The advocates, who previously had pinned their hopes on this study, now criticize its design and are lobbying for a congressional Breast Cancer and Environmental Research Act, which would authorize the spending of $\$ 30$ million per year for 5 years for further research into the relation between breast cancer and environmental toxicants.

\section{The causes of cancer clusters}

What are the reasons for these disturbing and costly clusters? To address this question, it is useful to review the available data on how much of the breast cancer burden may be due to established risk factors.

Madigan and colleagues [5] calculated that if every woman in the United States had the most favorable risk factor profile (e.g. early age at first childbirth, many children), then an estimated $59 \%$ of the breast cancer burden would still remain. (The confidence interval accompanying this estimate is wide, with anywhere from $20 \%$ to $98 \%$ of breast cancer cases remaining after this hypothetical change to an optimal distribution of risk factors.)

Several studies have evaluated the extent of regional differences in US breast cancer rates and have estimated the fraction of this variation attributable to established risk factors. Rates generally are lowest in the South, and highest in the Northeast and in the West [6]. Sturgeon and colleagues [7] found little difference in regional breast cancer mortality rates among young women, but larger differences among older women. Compared with death rates in the South, Sturgeon and colleagues noted a 15\% excess in the West and a 30\% excess in the Northeast. Approximately $50 \%$ of the excesses in the Northeast and Midwest, and $10 \%$ of the excess in the West, could be explained by regional differences in established risk factors. After adjustment for these factors, the magnitude of excess breast cancer mortality was $13 \%$ in the Northeast and West, and 8\% in the Midwest.

Robbins and colleagues [8] compared the prevalence of established risk factors in the San Francisco Bay area (high incidence) with that of other US areas. They concluded that the elevated incidence in the San Francisco Bay Area can be explained completely by regional differences in risk factors. Interestingly, Prehn and West [9] found rates similar to those in Marin County in California census block groups with similar socioeconomic characteristics to those in Marin County. Similarly, Laden and colleagues [10] found no regional differences in breast cancer incidence rates among a socioeconomically homogeneous cohort of US nurses. The findings suggest that much of the regional variation may reflect regional variation in socioeconomic status.

Taken together, these studies suggest that there is interpersonal variation in incidence and mortality that is not completely explained by the variation in established risk factors. In fact, there is increasing evidence [11-13] of inherited variation in genes affecting breast cancer risk among women who do not carry mutations of the genes $B R C A 1$ and BRCA2.

Migrant groups of different ethnicities have settled in different areas of the United States. Because genetic factors vary with ethnicity, this geographic specificity suggests that individual genetic variation in risk is distributed nonrandomly across various geographic regions. This risk variation from one region to another is not taken into account when testing the null hypothesis that cancer rates in the given region equal those of other regions. The $P$ values for rejecting the null hypothesis assume that the incidence rate for a given age group is uniform for all women in the age group, regardless of their region of residence. A more appropriate null hypothesis would specify that the regional rate (itself an average of the rates of its residents) varies over regions according to some probability distribution. Tests of this 'regional variation null hypothesis' would produce fewer statistically significant clusters than do the existing 'uniform null hypothesis' tests. As long as the uniform null hypothesis is tested, clusters will continue to appear and continue to alarm the communities in which they occur. 


\section{Conclusion and unresolved issues}

What is the solution to this dilemma? One solution is to modify our statistical tests to accommodate the extrabinomial and extra-Poisson variation in risk from one geographic region to another. This will reduce the number of apparent clusters. However, it does not address the more important question: how can we unravel the reasons for geographic distribution of individual risk? To do this, we must understand the sources of interpersonal variation in cancer risks. Work on this issue is ongoing as cancer epidemiologists begin to understand the genetic factors associated with risk, and their interaction with the environment.

Meanwhile, the recent episodes in Marin County and Long Island raise the following critical question: what scientific evidence would convince breast cancer activists that the elevated rates in a community are not due to environmental toxicants? Will they one day conclude that the accumulated epidemiological and molecular evidence does not support a role for these toxicants, and that precious resources might better be spent fighting the disease in other ways? This is not a scientific question, but rather a social and psychological one. It concerns the level of evidence needed to dislodge an entrenched conviction, one vested with potent emotional force.

\section{Competing interests}

None declared.

\section{References}

1. Wrensch M, Chew T, Farren G, Barlow J, Belli F, Clarke C, Erdmann CA, Lee M, Moghadassi M, Peskin-Mentzer R, Quesenberry CP Jr, Souders-Mason V, Spence L, Suzuki M, Gould M: Risk factors for breast cancer in a population with high incidence rates. Breast Cancer Res 2003, 5:R88-R102.

2. Clarke CA, Glaser SL, West DW, Ereman RR, Erdmann CA, Barlow JM, Wrensch MR: Breast cancer incidence and mortality trends in an affluent population: Marin County, California, USA, 1990-1999. Breast Cancer Res 2002, 4:R13-R19.

3. Gammon MD, Santella RM, Neugut Al, Eng SM, Teitelbaum SL, Paykin A, Levin B, Terry MB, Young TL, Wang LW, Wang O, Britton JA, Wolff MS, Stellman SD, Hatch M, Kabat GC, Senie R, Garbowski G, Maffeo C, Montalvan P, Berkowitz G, Kemeny M, Citron M, Schnabel F, Schuss A, Hajdu S, Vinceguerra V: Environmental toxins and breast cancer on Long Island. I. Polycyclic aromatic hydrocarbon DNA adducts. Cancer Epidemiol Biomarkers Prev 2002, 11:677-685.

4. Gammon MD, Wolff MS, Neugut Al, Eng SM, Teitelbaum SL, Britton JA, Terry MB, Levin B, Stellman SD, Kabat GC, Hatch M, Senie R, Berkowitz G, Bradlow HL, Garbowski G, Maffeo C, Montalvan P, Kemeny M, Citron M, Schnabel F, Schuss A, Hajdu S, Vinceguerra V, Niguidula N, Ireland K, Santella RM: Environmental toxins and breast cancer on Long Island. II. Organochlorine compound levels in blood. Cancer Epidemiol Biomarkers Prev 2002, 11:686-697.

5. Madigan MP, Ziegler RG, Benichou J, Byrne C, Hoover RN: Proportion of breast cancer cases in the United States explained by well-established risk factors. J Natl Cancer Inst 1995, 87: 1681-1685.

6. Kulldorff M, Feuer EJ, Miller BA, Freedman LS: Breast cancer clusters in the northeast United States: a geographic analysis. Am J Epidemiol 1997, 146:161-170.

7. Sturgeon SR, Schairer C, Gail M, McAdams M, Brinton LA, Hoover RN: Geographic variation in mortality from breast cancer among white women in the United States. J Natl
8. Robbins AS, Brescianini S, Kelsey JL. Regional differences in known risk factors and the higher incidence of breast cancer in San Francisco. J Natl Cancer Inst 1997, 89:960-965.

9. Prehn AW, West DW: Evaluating local differences in breast cancer incidence rates: a census-based methodology (United States). Cancer Causes Control 1998, 9:511-517.

10. Laden F, Spiegelman D, Neas LM, Colditz GA, Hankinson SE, Manson JE, Byrne C, Rosner BA, Speizer FE, Hunter DJ: Geographic variation in breast cancer incidence rates in a cohort of U.S. women. J Nat/ Cancer Inst 1997, 89:1373-1378.

11. Pharoah PD, Antoniou A, Bobrow M, Zimmern RL, Easton DF, Ponder BA: Polygenic susceptibility to breast cancer and implications for prevention. Nat Genet 2002, 31:33-36.

12. Peto J, Mack TM: High constant incidence in twins and other relatives of women with breast cancer. Nat Genet 2000, 26: 411-414.

13. Dite GS, Jenkins MA, Southey MC, Hocking JS, Giles GG McCredie MR, Venter DJ, Hopper JL: Familial risks, early-onset breast cancer, and BRCA1 and BRCA2 germline mutations. $J$ Natl Cancer Inst 2003, 95:448-457.

\section{Correspondence}

Alice S Whittemore, $\mathrm{PhD}$, Stanford University School of Medicine, Stanford, CA 94305, USA. Te: +1 650723 5460; fax: +1 650725 6951; e-mail: alicesw@stanford.edu 